\title{
Plant cell wall integrity maintenance as an essential component of biotic stress response mechanisms
}

\author{
Thorsten Hamann* \\ Division of Cell and Molecular Biology, Department of Life Sciences, Imperial College London, London, UK
}

\section{Edited by:}

Jose Manuel Estevez, University of Buenos Aires and CONICET, Argentina

\section{Reviewed by:}

Kian Hématy, Institut National de la

Recherche Agronomique, France

Staffan Persson,

Max-Planck-Gesellschaft, Germany

\section{${ }^{*}$ Correspondence:}

Thorsten Hamann, Division of Cell and Molecular Biology, Department of Life Sciences, Imperial College London,

Sir Alexander Fleming Building (608),

South Kensington Campus, London

SW7 2AZ, UK. e-mail:

thamann@imperial.ac.uk
Plant cell walls provide structural support during development and represent together with the cuticle the first line of defense against biotic and abiotic stress. In recent years, evidence has accumulated that a dedicated plant cell wall integrity (CWI) maintenance mechanism exists. This mechanism monitors and maintains functional integrity of the cell wall during different biological processes. The available data suggest that it may represent a component of the stress response mechanisms underlying biotic and abiotic stress responses, which has not been identified previously as a distinct mechanism. Here I will review the available evidence regarding the mode of action of the CWI maintenance mechanism and discuss its role in the context of biotic plant stress response mechanisms.

Keywords: plant cell wall integrity, biotic stress, plant pathogen

\section{INTRODUCTION}

Plant cells need to maintain the functional integrity of their walls during cell morphogenesis and exposure to biotic/abiotic stress. The available evidence suggests that a dedicated plant cell wall integrity (CWI) maintenance mechanism exists (Wolf et al., 2011). While our understanding of the mechanisms regulating stress responses and morphogenesis has increased significantly, our knowledge regarding the processes maintaining CWI is still limited. In the last years several reviews have been published on the plant CWI maintenance mechanism illustrating the increased interest in this area (Humphrey et al., 2007; Hematy et al., 2009; Ringli, 2010; Seifert and Blaukopf, 2010). A recently published review focuses on CWI maintenance during plant cell wall morphogenesis (Wolf et al., 2011). Similarities between the yeast and plant CWI maintenance mechanisms have also been reviewed (Hamann and Denness, 2011). Therefore, the available knowledge regarding CWI maintenance during plant development and in yeast will be covered here only briefly to provide a conceptual framework regarding cellular processes involved and to illustrate the degree of functional conservation between species. This review will focus on recent developments regarding the role of CWI maintenance during biotic stress responses. It will discuss how CWI maintenance could have a previously unrecognized role in the perception of and response to biotic stress.

\section{SIMILARITIES AND DIFFERENCES BETWEEN YEAST AND PLANT CELL WALL INTEGRITY MAINTENANCE MECHANISMS}

While both plant and yeast cells are enveloped by cell walls, certain important differences exist that affect the biological role and function of the plant CWI maintenance mechanism. Yeast unlike plant cells, do not have to deal with biotic stress. In addition, plant cell walls are structurally and chemically more complex than the yeast cell wall. This means that in plant cells the sheer number of cell wall-related signaling events during development and plantenvironment interaction could disguise the activity of a dedicated plant CWI maintenance mechanism.

The yeast CWI monitoring and maintenance network is quite complex, providing an indication of the possible complexity of the plant CWI maintenance network. By combining inputs from a turgor pressure sensor (SLN1), mechano-perception (MID1/CCH1), and dedicated cell wall damage (CWD) sensors (WSC1, 2, 3, MID2, MTL1) the yeast CWI maintenance network generates signals that permit highly specific responses to any challenge that impairs the functional integrity of the yeast cell wall. The available phenotypic and genetic data also implicate turgor pressure, mechano-perception, and CWD detection in plant CWI maintenance (Hamann et al., 2009; Denness et al., 2011). Interestingly, ARABIDOPSIS HISTIDINE KINASE1 (AHK1) and CYTOKININ RECEPTOR1/ARABIDOPSIS HISTIDINE KINASE4 (CRE1/AHK4) can at least partially rescue a yeast strain with a loss of function allele in SLN1 (Urao etal., 1999; Inoue etal., 2001). In addition, expression of the Arabidopsis thaliana MID1 COMPLEMENTING ACTIVITY 1 and $2(M C A 1,2)$ genes rescues a MID1-deficient yeast strain suggesting that they could function as stretch-activated calcium channels (Nakagawa et al., 2007; Yamanaka et al., 2010). Up to now no functional homologues for the yeast CWD sensors have been identified in plants. In yeast, the signals generated by the sensors are relayed to the response genes via different signaling cascades involving CALCINEURIN (MID1/CCH1); RHO1/MPK1 (WSC1, MID2), and YPD1 (SLN1) (Levin, 2005). Transcription factors mediating the response are SKN7, RLM1, and SWI4/6 (Levin, 2005). The response can involve activation of genes required for cell wall biosynthetic processes, remodeling of the cytoskeleton, and cell cycle progression. The available data suggest both organizational and functional 
similarities between the yeast and plant CWI maintenance mechanism while also highlighting how signals from mechanical and chemical sensors regulate jointly the CWD response.

\section{COMPOSITION AND STRUCTURE OF THE PLANT CELL WALL}

The plant cell wall is comparable to an exoskeleton surrounding the plant cell and providing both structural support and protection from biotic as well as abiotic stresses. It consists of cellulose microfibrils, pectin, hemicelluloses, proteins, and in certain cases lignin (Somerville et al., 2004). Plant cell walls are divided into primary (laid down during cell elongation/differentiation) and secondary (formed after cell morphogenesis is concluded) walls. In parallel, dependent on the presence of certain polysaccharides type I and type II cell walls are distinguished (Popper et al., 2011). Cellulose microfibrils are the main load bearing elements, which are cross-linked to hemicelluloses and (in vitro) to pectin (DickPerez et al., 2011). Hemicelluloses and pectin also form direct links creating a matrix in which the microfibrils are embedded like the steel mesh in a concrete wall. Pectic polysaccharides like homogalacturonan $(\mathrm{HG})$ are connected by calcium bridges between dimethyl-esterified parts of the molecules or through borate ester linkages in the case of rhamnogalacturonan II (RG II). They represent important cell wall components during morphogenesis facilitating cell expansion and plant-pathogen interaction (Hahn et al., 1981; Bellincampi et al., 1996). In the latter situation they are targeted by pathogen-derived cell wall degrading enzymes (polygalacturonases), which generate oligogalacturonides (OGAs) from HG (Hahn et al., 1981; Kars et al., 2005). Biologically active OGAs consist of chains of 9-15 galacturonic acid (GalA) monomers and can function as signaling molecules (see below).

During secondary cell wall formation monolignols (precursors for lignin) are secreted into the cell wall space and randomly cross-linked (Vanholme et al., 2010). The cross-linking is dependent on the availability of reactive oxygen species (ROS) generated by laccases and peroxidases. This process reinforces the wall against pathogen infection, waterproofs it, and increases structural integrity (Tronchet et al., 2010; Vanholme et al., 2010). Reduction of cellulose biosynthesis during primary cell wall formation through genetic or chemical means leads to lignin production (Ellis et al., 2002; Hamann et al., 2009). This highlights the ability of the cell to adapt to changes in cell wall composition and provides evidence for the existence of a CWI maintenance mechanism.

\section{THE PLANT CWI MAINTENANCE MECHANISM AS A COMPONENT OF THE BIOTIC STRESS RESPONSE}

Plant cell walls are capable of adjusting their composition and structure in response to pathogen infection (Dong et al., 2008). A mutation in (CELLULOSE SYNTHASEA3, CESA3) a subunit of the cellulose synthase complex leads to ectopic production of lignin, i.e., replacement of a missing load bearing cell wall component by another one (Cano-Delgado et al., 2000). Follow up studies found that inhibition of cellulose biosynthesis during primary cell wall formation either through mutations like constitutive expression of VSP1 (cev1) and ectopic lignification1 (eli1) or inhibitors such as isoxaben results in transcriptional activation of stress response mechanisms; ectopic production of ethylene (ET), salicylic acid (SA), jasmonic acid (JA), callose, and ROS as well as changes in cell wall composition and structure (Ellis et al., 2002; Cano-Delgado et al., 2003; Manfield et al., 2004; Hamann et al., 2009). The experiments also showed that the response to CWD consists of early and late stages reminiscent of the response to pathogen infection (Denness et al., 2011). During the early stage, ROS- and calcium-based signaling cascades are required for initiating the response to CWD (Denness et al., 2011). Interestingly, 1-aminocyclopropane-1-carboxylic acid (ACC, an ET precursor) and not ET itself seems to be acting as signaling substance during the early response to isoxaben with inhibition of cell expansion being an active process and not simply an automatic consequence of cellulose biosynthesis inhibition (Tsang et al., 2011). During the late stage, responses to CWD-like lignin deposition are initiated and the extent of lignin formation is apparently modulated by a negative feedback loop formed by ROS and JA (Denness et al., 2011). A combination of genetic and phenotypic analysis has implicated the NADPH oxidases RESPIRATORY BURST OXIDASE HOMOLOGD and $F(R B O H D, F)$, the serine/threonine kinase OXIDATIVE SIGNAL INDUCIBLE1 (OXI1), MCA1, the receptor-like kinase (RLK) THESEUS1 (THE1) as well as the JA biosynthesis genes ALLENE OXIDE SYNTHASE (AOS) and JASMONIC ACID RESISTANT1 (JAR1) in the signaling mechanism mediating the response to CWD in Arabidopsis seedlings. Interestingly, the cev1 mutation that affects cellulose biosynthesis during primary cell wall formation also causes enhanced resistance to infection by different powdery mildews (Erysiphe orontii, E. cichoracearum, and Oidium lycopersicum; Ellis and Turner, 2001).

A screen for mutants causing resistance to powdery mildew infection provides further evidence of the close relationship between plant cell walls and pathogen resistance (Vogel and Somerville, 2000). Three of the powdery mildew resistance (PMR) mutants that have been identified on the molecular level affect genes involved in cell wall biosynthetic processes. PMR4 encodes a callose synthase, PMR5 a gene of unknown function required for pectin production and PMR6 a pectate lyase (Vogel et al., 2002, 2004; Nishimura et al., 2003). pmr4 resistance seems to be mediated via hyper-activation of SA signaling, whereas pmr5 and 6 resistance phenotypes are independent of JA, SA, and ET signaling. Mutations in IRREGULARXYLEM1 (IRX1/CESA8), 3 (IRX3/CESA7), and 5 (IRX5/CESA4) impair cellulose biosynthesis during secondary cell wall formation and cause enhanced resistance to the soil borne bacterium Ralstonia solanacearum and the necrotrophic fungus Plectosphaerella cucumerina (HernandezBlanco et al., 2007). Mutations affecting cellulose biosynthesis during primary cell wall formation (cesa1, 3, 6) or other components of the secondary cell wall ( $p m r 5$, pmr6) did not cause enhanced resistance to the same pathogens. Genetic analysis showed that the enhanced resistance in cesa4, 7, 8 is independent of JA, SA, and ET-based signaling mechanisms. Results from expression profiling experiments and genetic analysis using different abscisic acid (ABA) mutants ( $A B A$ insensitive 1-1; 2-1; ABA1-6) suggest that $\mathrm{ABA}$ is mediating developmental and pathogen resistance phenotypes caused by the irx mutants. However, it remains to be determined if the ABA involvement is direct or a secondary effect due to water stress caused by problems with xylem cell wall 
formation in the mutants. To summarize, these results suggest distinct resistance signaling cascades are induced by defects in primary and secondary cell wall formation as well as for different secondary cell wall components. They also highlight the direct impact of changes in cell wall composition/structure on the response to pathogen infection.

\section{SIGNALING MECHANISMS AND SENSORS IMPLICATED IN PLANT CWD PERCEPTION}

The mode of action of the plant cell wall maintenance mechanism is not well understood. Based on the knowledge from yeast, chemical and physical signals could act as indicators for the functional integrity of the plant cell wall either individually or jointly. By combining these different types of signal the plant cell would receive precise information regarding the state of its cell wall and the exact type of CWI impairment occurring. Physical signals could be generated by stretching of the plasma membrane due to a weakened cell wall that cannot resist the high turgor pressure levels within a plant cell or a plasma membrane that is displaced relatively to the cell wall. These events could be detected by stretch-activated or mechanosensitive channel proteins that lead to calcium influx into the cytoplasm, indicating CWD. Sensor candidates could be encoded by members of the mechanosensitive channels of small conductance (MscS)-like (MSL) gene family like MSL 9 and 10 affect mechano-perception in protoplasts derived from Arabidopsis root cells (Haswell et al., 2008). Another candidate of interest is the putative stretch-activated calcium channel MCA1 is required for CWD-induced lignin deposition. Interestingly, all isoxabeninduced CWD phenotypes can be suppressed by provision of osmotic support suggesting that changes in turgor pressure due to a weakened cell wall could result in signal generation via turgor pressure sensors (Hamann et al., 2009; Denness et al., 2011). While AHK1 and 4/CRE1 can function as osmosensors in yeast and have been implicated in abiotic stress responses, no clear evidence exists implicating them in CWD perception in plants (Urao et al., 1999; Inoue et al., 2001; Tran et al., 2007). In addition, AHK4/CRE1 has been shown to function as a cytokinin receptor (Inoue et al., 2001). Therefore, the question that needs to be resolved at this point is if turgor pressure is a passive element in the process (generating cell wall fragments due to a weakened cell wall) or an active component that is being monitored and provides input into the process.

The plant cell wall contains a large number of components that could generate chemical signals (ligands) indicative of CWD or general danger signals. The term damage associated molecular patterns (DAMPs) has been coined to describe such ligands and the number of possible DAMPs originating in plant cell walls is rather large (Zipfel, 2009). Here I will focus on the best-characterized group of signals, which are probably OGAs. They can be generated through degradation of $\mathrm{HG}$ by pathogen-derived enzymes (Kars et al., 2005; Ferrari et al., 2008). OGAs have been shown to induce gene expression changes, stomatal closure, production of ET, and ROS as well as cell wall reinforcement (Denoux et al., 2008; Ferrari et al., 2008). A hybrid kinase consisting of the extra cellular domain of WALL-ASSOCIATED KINASE1 (WAK1) and the intracellular domain of elongation factor Tu receptor (EFR) kinase can bind OGAs and activate defense responses (Brutus et al., 2010).
WAK1 belongs to a family of five WAK genes encoding plasma membrane-localized Ser/Thr kinases that have been implicated in response to pathogen infection and regulation of cell elongation (Kohorn et al., 2011). The effects of the chimeric WAK1 kinase on pathogen resistance suggest that OGAs and WAKs represent an in vivo ligand-receptor pair. Results from the analysis of a dominant active WAK2 allele suggest the CWD signals perceived by WAKs could be relayed to downstream response genes through MAPKINASE6 (MPK6) (Kohorn et al., 2009, 2011). Interestingly, WAK2 has also been implicated in regulation of invertase activity and turgor pressure during cell elongation (Kohorn et al., 2006). However, there is currently no confirmation that WAKs are actively involved in CWI maintenance.

In Arabidopsis, more than 600 RLKs have been identified and a large number of them have been implicated in developmental and stress response processes (Shiu and Bleecker, 2001). I will focus here on several kinases that have been implicated in CWD perception and/or pathogen response. Most of the RLKs implicated in CWI maintenance [THE1, HERCULES1 (HERK1), FERONIA (FER)] belong to the Catharanthus roseus RLK1 (CrRLK1)-like protein family, which has 17 members in Arabidopsis. THE1 was isolated as a suppressor of the cellulose-deficient cesa 6 procuste (prc) mutant, which exhibits a hypocotyl elongation defect (Hematy et al., 2007). Although the1 suppresses the elongation defect, the cellulose deficiency is not reduced. Subsequently it has been shown that THE1 is required for cellulose biosynthesis inhibition-induced ROS production and lignification in the root elongation zone (Denness et al., 2011). THE1, HERK1, and FER have been implicated in brassinosteroid-induced cell elongation (Guo et al., 2009; Deslauriers and Larsen, 2010). Both FER and NORTIA/MILDEW RESISTANCE LOCUS O 7 (MLO7; a seventransmembrane domain protein involved in powdery mildew resistance) are required for successful fertilization and resistance to infection by Golovinomyces (syn. Erysiphe) orontii (Kessler et al., 2010). Interestingly, ROPGEF (guanine-exchange factors) proteins have been identified as targets of FER activity (Duan et al., 2010). ROPGEFs are required for the activation of Rho GTPases, which in turn activate NADPH oxidases like RBOHD/F. These results suggest the same molecular components could mediate cell-cell interaction during development and plant-pathogen interaction.

Heterotrimeric G-proteins ( $\mathrm{G} \alpha, \mathrm{G} \beta, \mathrm{G} \gamma$ ) form a highly conserved signaling complex that has been implicated in signal transduction during development and stress responses in mammals, yeast, and plants (Digby et al., 2006; Temple and Jones, 2007). In Arabidopsis, five genes GPA1 (G $\alpha)$, AGB1 (G $\beta$ ), AGG1, 2, 3 $(G \gamma 1,2,3)$ encode the subunits of the complex (Thung et al., 2011). Recently, it has been reported that mutations in $A G G 1,2$, and $A G B 1$ apparently cause enhanced susceptibility to infection with P. cucumerina (Delgado-Cerezo et al., 2011). A combination of metabolomic and microarray-based expression profiling studies of the mutants established that the pathogen phenotype is independent of SA, JA, ABA, and ET signaling cascades. Interestingly, a large number of cell wall biosynthetic/modifying genes are mis-regulated in $a g b 1$ and $a g g 12$ plants. Analysis of cell wall composition/structure in these plants found reduced xylose contents in the mutants compared to wildtype. 
To summarize, the available evidence supports the notion that the plant cell wall is an integral component contributing to pathogen response mechanisms and illustrates the influence of cell wall defects on infection. Specific signaling cascades seem to mediate the response to particular cell wall defects, which in turn affect the response to necrotrophic or biotrophic pathogens. More importantly the data presented above allow correlation between certain types of cell wall defects, and not only signaling cascades but also resistance phenotypes. Mutations in CESA4, 7, 8, AGG1, 2, and $A G B 1$ affect resistance to necrotrophs and are independent of phytohormone-based signaling cascades. pmr5, 6 plants exhibit resistance to biotrophs and also do not rely on phytohormonebased signaling cascades. pmr4 affects resistance to biotrophs and resistance depends on the integrity of the SA signaling cascade. cesa 3 plants show enhanced JA, ET biosynthesis, and resistance to biotrophs.

The available data allow different explanations for the specific effects on pathogen resistance observed. The cell wall composition/structure changes could prevent pathogen colonization simply because the infection machinery of the pathogen is too specialized to breach the chemically modified cell wall. However, no functional pathogen response mechanisms should be

\section{REFERENCES}

Bellincampi, D., Cardarelli, M., Zaghi, D., Serino, G., Salvi, G., Gatz, C., Cervone, F., Altamura, M. M., Costantino, P., and Lorenzo, G. D. (1996). Oligogalacturonides prevent rhizogenesis in rolB-transformed tobacco explants by inhibiting auxininduced expression of the rolB gene. Plant Cell 8, 477-487.

Brutus, A., Sicilia, F., Macone, A., Cervone, F., and De Lorenzo, G. (2010). A domain swap approach reveals a role of the plant wall-associated kinase 1 (WAK1) as a receptor of oligogalacturonides. Proc. Natl. Acad. Sci. U.S.A. 107, 9452-9457.

Cano-Delgado, A., Penfield, S., Smith, C., Catley, M., and Bevan, M. (2003). Reduced cellulose synthesis invokes lignification and defense responses in Arabidopsis thaliana. Plant J. 34, 351-362.

Cano-Delgado, A. I., Metzlaff, K., and Bevan, M. W. (2000). The eli1 mutation reveals a link between cell expansion and secondary cell wall formation in Arabidopsis thaliana. Development 127, 3395-3405.

Delgado-Cerezo, M., Sanchez-Rodriguez, C., Escudero, V., Miedes, E., Fernandez, P. V., Jorda, L., Hernandez-Blanco, C., SanchezVallet, A., Bednarek, P., SchulzeLefert, P., Somerville, S., Estevez, J. M., Persson, S., and Molina, A. (2011). Arabidopsis heterotrimeric Gprotein regulates cell wall defense and resistance to necrotrophic fungi. $\mathrm{Mol}$. Plant 5, 98-114.
Denness, L., McKenna, J. F., Segonzac, C., Wormit, A., Madhou, P., Bennett, M., Mansfield, J., Zipfel, C., and Hamann, T. (2011). Cell wall damage-induced lignin biosynthesis is regulated by a ROS- and jasmonic acid dependent process in Arabidopsis thaliana. Plant Physiol. 156, 1364-1374.

Denoux, C., Galletti, R., Mammarella, N., Gopalan, S., Werck, D., De Lorenzo, G., Ferrari, S., Ausubel, F. M., and Dewdney, J. (2008). Activation of defense response pathways by OGs and Flg22 elicitors in Arabidopsis seedlings. Mol. Plant 1, 423-445.

Deslauriers, S. D., and Larsen, P. B. (2010). FERONIA is a key modulator of brassinosteroid and ethylene responsiveness in Arabidopsis hypocotyls. Mol. Plant 3, 626-640.

Dick-Perez, M., Zhang, Y., Hayes, J., Salazar, A., Zabotina, O. A., and Hong, M. (2011). Structure and interactions of plant cell-wall polysaccharides by two- and threedimensional magic-angle-spinning solid-state NMR. Biochemistry 50, 989-1000. doi: 10.1021/bi101795q

Digby, G. J., Lober, R. M., Sethi, P. R., and Lambert, N. A. (2006). Some G protein heterotrimers physically dissociate in living cells. Proc. Natl. Acad. Sci. U.S.A. 103, 17789-17794.

Dong, X., Hong, Z., Chatterjee, J., Kim, S., and Verma, D. P. (2008). Expression of callose synthase genes and its connection with NPR1 signaling pathway during pathogen infection. Planta 229, 87-98.

required for this possibility. Another option is that the cell wall mutants cause defects similar to those occurring during infection by particular pathogens, i.e., simulate infection by necrotrophs or biotrophs. This would cause early/constant activation of the CWI maintenance/defense mechanism, which "primes" plant immunity thus making successful infection more difficult. The latter would explain both the specificity of the responses observed and dependence on particular signaling mechanisms. Therefore, studies focusing on the effects of particular cell wall defects on pathogen resistance and the mode of action of the CWI maintenance mechanism could facilitate research into biotic stress response. The reason being, that by removing the potentially multiple effects of the pathogen during infection, they reduce the complexity of the interaction and should therefore allow novel insights into the mechanisms responsible for detection of infection and/or physical damage.

\section{ACKNOWLEDGMENTS}

The author would like to thank John Mansfield and Issariya Chairam for critical reading of the manuscript and helpful comments. Research in the Hamann lab is supported by the Gatsby Foundation, BBSRC, and the FP7 framework program.

Duan, Q., Kita, D., Li, C., Cheung A. Y., and Wu, H. M. (2010). FERONIA receptor-like kinase regulates RHO GTPase signaling of root hair development. Proc. Natl. Acad. Sci. U.S.A. 107, 17821-17826.

Ellis, C., Karafyllidis, I., Wasternack, C., and Turner, J. G. (2002). The Arabidopsis mutant cev1 links cell wall signaling to jasmonate and ethylene responses. Plant Cell 14, 1557-1566.

Ellis, C., and Turner, J. G. (2001). The Arabidopsis mutant cev1 has constitutively active jasmonate and ethylene signal pathways and enhanced resistance to pathogens. Plant Cell 13, 1025-1033.

Ferrari, S., Galletti, R., Pontiggia, D., Manfredini, C., Lionetti, V., Bellincampi, D., Cervone, F., and De Lorenzo, G. (2008). Transgenic expression of a fungal endopolygalacturonase increases plant resistance to pathogens and reduces auxin sensitivity. Plant Physiol. 146, 669-681.

Guo, H., Li, L., Ye, H., Yu, X., Algreen, A., and Yin, Y. (2009). Three related receptor-like kinases are required for optimal cell elongation in Arabidopsis thaliana. Proc. Natl. Acad. Sci. U.S.A. 106, 7648-7653.

Hahn, M. G., Darvill, A. G., and Albersheim, P. (1981). Host-pathogen interactions: XIX. The endogenous elicitor, a fragment of a plant cell wall polysaccharide that elicits phytoalexin accumulation in soybeans. Plant Physiol. 68, 1161-1169.
Hamann, T., Bennett, M., Mansfield, J., and Somerville, C. (2009). Identification of cell-wall stress as a hexosedependent and osmosensitive regulator of plant responses. Plant J. 57, 1015-1026.

Hamann, T., and Denness, L. (2011) Cell wall integrity maintenance in plants: lessons to be learned from yeast? Plant Signal. Behav. 6, 1-5.

Haswell, E. S., Peyronnet, R., BarbierBrygoo, H., Meyerowitz, E. M., and Frachisse, J. M. (2008). Two MscS homologs provide mechanosensitive channel activities in the Arabidopsis root. Curr. Biol. 18 , 730-734.

Hematy, K., Cherk, C., and Somerville, S. (2009). Host-pathogen warfare at the plant cell wall. Curr. Opin. Plant Biol. 12, 406-413.

Hematy, K., Sado, P. E., Van Tuinen, A., Rochange, S., Desnos, T., Balzergue, S., Pelletier, S., Renou, J. P., and Hofte, H. (2007). A receptorlike kinase mediates the response of Arabidopsis cells to the inhibition of cellulose synthesis. Curr. Biol. 17 922-931.

Hernandez-Blanco, C., Feng, D. X., Hu, J., Sanchez-Vallet, A., Deslandes, L., Llorente, F., BerrocalLobo, M., Keller, H., Barlet, X., Sanchez-Rodriguez, C., Anderson, L. K., Somerville, S., Marco, Y. and Molina, A. (2007). Impairment of cellulose synthases required for Arabidopsis secondary cell wall formation enhances disease resistance. Plant Cell 19, 890-903. 
Humphrey, T. V., Bonetta, D. T., and Goring, D. R. (2007). Sentinels at the wall: cell wall receptors and sensors. New Phytol. 176, 7-21.

Inoue, T., Higuchi, M., Hashimoto, Y., Seki, M., Kobayashi, M., Kato, T., Tabata, S., Shinozaki, K., and Kakimoto, T. (2001). Identification of CRE1 as a cytokinin receptor from Arabidopsis. Nature 409, 1060-1063.

Kars, I., Krooshof, G. H., Wagemakers, L., Joosten, R., Benen, J. A., and van Kan, J. A. (2005). Necrotizing activity of five Botrytis cinerea endopolygalacturonases produced in Pichia pastoris. Plant J. 43, 213-225.

Kessler, S. A., Shimosato-Asano, H., Keinath, N. F., Wuest, S. E., Ingram, G., Panstruga, R., and Grossniklaus, U. (2010). Conserved molecular components for pollen tube reception and fungal invasion. Science 330, 968-971.

Kohorn, B. D., Johansen, S., Shishido, A., Todorova, T., Martinez, R., Defeo, E., and Obregon, P. (2009). Pectin activation of MAP kinase and gene expression is WAK2 dependent. Plant J. 60, 974-982.

Kohorn, B. D., Kobayashi, M., Johansen, S., Riese, J., Huang, L. F., Koch, K., Fu, S., Dotson, A., and Byers, N. (2006). An Arabidopsis cell wall-associated kinase required for invertase activity and cell growth. Plant J. 46, 307-316.

Kohorn, B. D., Kohorn, S. L., Todorova, T., Baptiste, G., Stansky, K., and McCullough, M. (2011). A dominant allele of Arabidopsis pectin-binding wall-associated kinase induces a stress response suppressed by MPK6 but not MPK3 mutations. Mol. Plant. doi: $10.1093 / \mathrm{mp} / \mathrm{ssr} 096$

Levin, D. E. (2005). Cell wall integrity signaling in Saccharomyces cerevisiae. Microbiol. Mol. Biol. Rev. 69, 262-291.

Manfield, I. W., Orfila, C., McCartney, L., Harholt, J., Bernal, A. J., Scheller, H. V., Gilmartin, P. M., Mikkelsen, J. D., Paul Knox, J., and Willats, W. G. (2004). Novel cell wall architecture of isoxabenhabituated Arabidopsis suspensioncultured cells: global transcript profiling and cellular analysis. Plant J. 40, 260-275.

Nakagawa, Y., Katagiri, T., Shinozaki, K., Qi, Z., Tatsumi, H., Furuichi, T., Kishigami, A., Sokabe, M., Kojima, I., Sato, S., Kato, T., Tabata, S., Iida, K., Terashima, A., Nakano, M., Ikeda, M., Yamanaka, T., and Iida, H. (2007). Arabidopsis plasma membrane protein crucial for $\mathrm{Ca}^{2+}$ influx and touch sensing in roots. Proc. Natl. Acad. Sci. U.S.A. 104, 3639-3644.

Nishimura, M. T., Stein, M., Hou, B. H., Vogel, J. P., Edwards, H., and Somerville, S. C. (2003). Loss of a callose synthase results in salicylic aciddependent disease resistance. Science 301, 969-972.

Popper, Z. A., Michel, G., Herve, C., Domozych, D. S., Willats, W. G., Tuohy, M. G., Kloareg, B., and Stengel, D. B. (2011). Evolution and diversity of plant cell walls: from algae to flowering plants. Ann. Rev. Plant Biol. 62, 567-590.

Ringli, C. (2010). Monitoring the outside: cell wall-sensing mechanisms. Plant Physiol. 153, 1445-1452.

Seifert, G. J., and Blaukopf, C. (2010). Irritable walls: the plant extra cellular matrix and signaling. Plant Physiol. 153, 467-478.

Shiu, S. H., and Bleecker, A. B. (2001). Receptor-like kinases from Arabidopsis form a monophyletic gene family related to animal receptor kinases. Proc. Natl. Acad. Sci. U.S.A. 98, 10763-10768.

Somerville, C., Bauer, S., Brininstool, G., Facette, M., Hamann, T., Milne, J., Osborne, E., Paredez, A., Persson, S., Raab, T., Vorwerk, S., and Youngs, H. (2004). Toward a systems approach to understanding plant cell walls. Science 306, 2206-2211.

Temple, B. R., and Jones, A. M. (2007). The plant heterotrimeric G-protein complex. Ann. Rev. Plant Biol. 58, 249-266.

Thung, L., Trusov, Y., Chakravorty, D., and Botella, J. R. (2011). $\mathrm{G} \gamma 1+\mathrm{G} \gamma 2+\mathrm{G} \gamma 3=\mathrm{G} \beta$ : the search for heterotrimeric G-protein gamma subunits in Arabidopsis is over. J. Plant Physiol. 169, 542-545.

Tran, L. S., Urao, T., Qin, F., Maruyama, K., Kakimoto, T., Shinozaki, K., and Yamaguchi-Shinozaki, K. (2007). Functional analysis of $A H K 1 / A T H K 1$ and cytokinin receptor histidine kinases in response to abscisic acid, drought, and salt stress in Arabidopsis. Proc. Natl. Acad. Sci. U.S.A. 104 20623-20628.

Tronchet, M., Balague, C., Kroj, T., Jouanin, L., and Roby, D. (2010). Cinnamyl alcohol dehydrogenases-C and $\mathrm{D}$, key enzymes in lignin biosynthesis, play an essential role in disease resistance in Arabidopsis. Mol. Plant Pathol. 11, 83-92.

Tsang, D. L., Edmond, C., Harrington, J. L., and Nuhse, T. S. (2011). Cell wall integrity controls root elongation via a general 1-aminocyclopropane-1carboxylic acid-dependent, ethyleneindependent pathway. Plant Physiol. 156, 596-604.

Urao, T., Yakubov, B., Satoh, R., Yamaguchi-Shinozaki, K., Seki, M., Hirayama, T., and Shinozaki, K. (1999). A transmembrane hybridtype histidine kinase in Arabidopsis functions as an osmosensor. Plant Cell 11, 1743-1754.

Vanholme, R., Demedts, B., Morreel, K. Ralph, J., and Boerjan, W. (2010). Lignin biosynthesis and structure. Plant Physiol. 153, 895-905.

Vogel, J., and Somerville, S. (2000). Isolation and characterization of powdery mildew-resistant Arabidopsis mutants. Proc. Natl. Acad. Sci. U.S.A. 97, 1897-1902.

Vogel, J. P., Raab, T. K., Schiff, C. and Somerville, S. C. (2002). PMR6, a pectate lyase-like gene required for powdery mildew susceptibility in Arabidopsis. Plant Cell 14, 2095-2106.

Vogel, J. P., Raab, T. K., Somerville, C. R., and Somerville, S. C. (2004). Mutations in PMR5 result in powdery mildew resistance and altered cell wall composition. Plant J. 40, 968-978.

Wolf, S., Hematy, K., and Hofte, H. (2011). Growth control and cell wall signaling in plants. Ann. Rev. Plant Biol. doi: 10.1146/annurev-arplant042811-105449

Yamanaka, T., Nakagawa, Y., Mori, K., Nakano, M., Imamura, T., Kataoka, H., Terashima, A., Iida, K., Kojima, I., Katagiri, T., Shinozaki, K., and Iida, H. (2010). MCA1 and MCA2 that mediate $\mathrm{Ca}^{2+}$ uptake have distinct and overlapping roles in Arabidopsis. Plant Physiol. 152, 1284-1296.

Zipfel, C. (2009). Early molecular events in PAMP-triggered immunity. Curr. Opin. Plant Biol. 12, 414-420.

Conflict of Interest Statement: The author declares that the research was conducted in the absence of any commercial or financial relationships that could be construed as a potential conflict of interest.

Received: 27 January 2012; accepted: 05 April 2012; published online: 23 April 2012.

Citation: Hamann T (2012) Plant cell wall integrity maintenance as an essential component of biotic stress response mechanisms. Front. Plant Sci. 3:77. doi: 10.3389/fpls.2012.00077

This article was submitted to Frontiers in Plant Physiology, a specialty of Frontiers in Plant Science.

Copyright (c) 2012 Hamann. This is an open-access article distributed under the terms of the Creative Commons Attribution Non Commercial License, which permits non-commercial use, distribution, and reproduction in other forums, provided the original authors and source are credited. 